\title{
LÍNGUA E LINGUAGEM: OS ARTIFÍCIOS E A VERDADE JURÍDICA
}

\author{
Jeannette Antonios Maman \\ Professora Doutora de Filosofia e Teoria Geral \\ do Direito da Faculdade de Direito da \\ Universidade de São Paulo
}

\begin{abstract}
Em nossas notações, é certo que algo é arbitrário, mas isto não é arbitrário: se já determinamos como arbitrariamente, então algo mais deve ser o caso. (Isso depende da essência da notação.) ${ }^{1}$

(Wittgenstein, Tractatus, 3.342.)
\end{abstract}

\begin{abstract}
Resumo:
Trata-se de esboço das trilhas que levam à compreensão das chamadas ciências da linguagem, na busca da interioridade do fenômeno jurídico.

Abstract:

This paper is an introduction to the language sciences study which is required to the search of the truth essence of law phenomenon.
\end{abstract}

Unitermos: língua; linguagem; signos arbitrários; filosofia do ser.

I. Roteiro para situar os termos da questão proposta.

Fazer ver com um gesto, no enfrentamento da situação por inteiro. Olhar à volta, sem fugir. Este é um existir heideggeriano, no canto de Hölderlin assim tratado: muitos têm pudor de ir às fontes.

A necessidade de desmistificar os modos herméticos de comunicação assinala a trilha acima proposta, aqui sugerida ao mundo jurídico.

$\mathrm{O}$ pequeno texto que se segue resiste à pretensão de ser didático, ao reconhecer-se apenas na ação motivadora que instiga e incita às investigações jusfilosóficas.

1. Tradução direta do texto original em alemão. 
Ao doloroso esforço de pensar! Semiologia, Semiótica, semiológico. Cipoal de palavras cuja origem grega semeîon dá as primeiras pistas: Semeîon = Sinal.

Alguns pontos de partida assinalam três dimensões para uma teoria da Semiose que pode ser informadora da comunicação jurídica como discurso. Tomamos o sentido de semiose pelo processo em que algo funciona como signo. Signo aqui é objeto ou acontecimento usado como menção para outro objeto ou acontecimento. Tem a significação genérica de símbolo, quando então podemos ver a distância entre o signo e o seu objeto, imposta pela semiologia.

Os cursos da via moderna como maneira oposta à via antiga de pensar que não podem ignorar Guilherme de Ockham (1290-1349) teólogo franciscano, por muitos considerado fundador da maneira moderna de pensar, levariam aos modos operacionais do que se pode considerar como "ciência" do Direito, que beneficiariam os operadores do Direito, atuais cientistas jurídicos. É essa via moderna que nos permite ver não exatamente as três dimensões da semiose mas antes o que nos parece ser a fragmentação de um fenômeno dividido segundo aspectos funcionais:

1. Função semântica: a da relação dos signos com os objetos a que se refere;

2. Função pragmática: que considera a relação com os intérpretes;

3. Função sintática: que considera a relação formal dos signos entre si.

II. Códigos Verbais e Códigos Jurídicos.

Que modo de expressão, no sentido de manifestação, tem o Direito lingua ou linguagem?

Quando a linguagem é reduzida à língua, perdemos o conteúdo semântico e damos à linguagem técnica e instrumental a qualificação de fala de uma competência específic $a^{2}$. Entretanto, se não resistimos a este poder de síntese, vamos nos perguntar: podemos falar do Direito como linguagem, ou no limite, se linguagem é reduzida à língua, o Direito seria um código artificial, gerado por signos arbitrários?

Exercita-se, neste modo de ser, mera função cujo endereço último é a Jurisprudência, através dos operadores jurídicos, agora tão estimados por suas possibilidades retóricas e de persuasão? É o exercício de um fazer (Geschäft) que se pode traduzir como negócio?

2. Expressão colhida como manifestação oral, em evento público, de sua Excelência, o professor Tercio Sampaio Ferraz Júnior. 
Para nos aproximarmos do pensamento contemporâneo de Wittgenstein tomamos das Investigações Filosóficas, para citar:

“Onde há sentido, deve haver ordem perfeita...
Deve haver ordem perfeita na mais vaga das
Proposições" (I,98).

" $O$ ideal deve ser encontrado na realidade. Enquanto não virmos como se encontra nela não entenderemos a natureza desse deve. Achamos que deve estar na realidade porque achamos que já o vimos" $(I, 10 I)$.

O recurso ao autor reforça a percepção de que, para além da "terapia acurada da linguagem" Wittgenstein fez filosofia.

III. Origens e atualidade do tema

É bem certo que não nos devemos preocupar com a datação dos termos. Basta que tenhamos seu sentido etimológico e a análise da qual os filósofos se ocuparam. Mas, antes de tudo, a atualidade das questões que se referem às expressões acima apontadas, bem como àquelas que se referem a neologismos ou novidades teóricas, $e$ esta atualidade que nos interessa.

Se, podemos atribuir a responsabilidade histórica pelas ciências da linguagem a Ferdinand de Saussure (1857-1913), o desenvolvimento do que hoje se pode conhecer como tal (ciências da linguagem) permite abordagens mais atuais.

A explicitação, por palavras, por signos, por sinais (sémeîon) que substituem as coisas, já era questão filosófica em Guilherme de Ockham (1290-1349), que reproduz, na sua teoria dos signos, a metafísica de Aristóteles. Mais que isto, já estava em Aristóteles (384-322 a.C.) e Platão (428-347 a.C.). Parmênides, vivendo entre os séculos VI e V a.C. já dissera: as palavras são etiquetas das coisas ilusórias.

Para Aristóteles um nome é um vocábulo semântico segundo convenção (não por natureza, mas por se tornar símbolo), assim, se a relação palavra/imagem mental é convencional, a relação imagem mental/palavra é natural.

Como fazer ciência (organizar nosso saber para resolver problemas de ordem prática), sem conhecer as coisas às quais as palavras se referem? 
Se a palavra é um signo artificial, há como diria Platão no "Sofista” a impossibilidade de se comunicar conhecimento das coisas através dos nomes.

Assim, já na filosofia aristotélica a linguagem tem estruturas naturais e necessárias, porque são as mesmas do ser que ela revela. Se lembrarmos Heidegger, a linguagem é a morada do ser.

Voltemos ao responsável original, no scu Curso de Lingüística, pela definição de língua: conjunto dos costumes lingüisticos que permitem a um sujeito, compreender e fazer-se compreender. O que decorre daí para o direito (o disponivel para o exercício do oficio jurídico)?. Poderíamos pensá-lo como um conjunto de signos lingüísticos intersubjetivos fala de uma competência especifica? Ora, se a fala é especifica de um conjunto organizado de signos, há um problema mal resolvido na intersubjetividade da linguagem - decorre da natureza das coisas, de convenção, de acordo, de escolha?

Podemos, no limite, entender que "a fala de uma competência específica é um código artificial" " 3 . Isto é o mesmo que dizer da arbitrariedade de todos os usos lingüísticos e por paradoxo, que todos são igualmente válidos. Dizer o que não é, é não dizer.

IV. O retorno à filosofia do ser e a pergunta pela coisa

Poucos sabem que Martin Heidegger depois de escrever Ser e Tempo (1927) e Kant e o problema da Metafísica (1929) não escreveu livro algum até 1947, quando publica a Carta sobre o Humanismo.

Logo em seguida (1950) é publicado Holzwege, cujo título original preferimos traduzir por Caminhos do lenhador, ao invés de Chemins qui ne mènent nulle part, como fazem os franceses. Isto porque os Caminhos levam à interioridade da floresta profunda (Holz), domínio inexplorado do pensamento.

Onde as trilhas vão c voltam, sinalizadas por um raciocínio que não é linear, mas situado na busca do interior da floresta, comprometidos em vivenciar a experiência, não sucumbimos ao acaso, mas tomamos o destino em nossas mãos, confrontados com as coisas que se nos estendem, resolutos para sermos o que somos, seres livres, na verdade sempre renovada, salvos da errância das falsas rotas, na persistência da resolução.

3. Ilem, à mesma ocasião. 
O que as coisas ${ }^{4}$ nos dizem? Abrimos picadas como caminhos do lenhador, aproximamo-nos e recuamos (às fontes!). Perdemos o pudor $\mathrm{e}$ vamos além das competências — vamos às coisas mesmas, nossa intenção manifesta-se em dois lugares: em relação a "sinal" e em relação à vivência.

Eis aí a virada lingüística a que nos propomos. Não se pode mais pensar o direito sem vivenciar a experiência dos fenômenos com os quais nos confrontamos.

Fugir a isso é nos negarmos, é instalar o principio da disjunção, separar o sujeito pensante e o objeto a ser conhecido.

Podemos reconhecer a crise do logos grego, mas nos negamos a instaurar o paradigma da esquizofrenia, como diria um analista de plantão, na observação dos homens e mulheres contemporâneos, estilhaçados em sua unidade, fragmentados em sua personalidade.

Impõe-se resistir às forças do niilismo, empregando a razão hermenêutica de Heidegger, sem deixarmos de cruzar neste trajeto com a razĩo fenomenológica de Husserl e a razão analítica de Wittgenstein.

Juntamos todos os "cacos" da racionalidade para re-compor o mosaico de um novo humanismo, expresso em linguagem autêntica.

São Paulo, agosto de 2003.

4. Tomamos a acepção da palavra coisa, em Heidegger. Uma coisa é o suporte subsistente de diversas propriedade que nela subsistem e se modificam. É ente existente na totalidade dos entes existentes no mundo. 
Bibliografia

DUCROT, Oswald; TODOROV, Tzvetan. Dicionário enciclopédico das ciências da linguagem, São Paulo, Perspectiva, 1988.

HEIDEGGER, Martin. Que é uma coisa? Lisboa, Edição 70, 1992. - Qu'est-ce qu'une chose? France, Gallimard, 1962.

Chemins qui ne mènent nulle part, France, Gallimard, 1962.

L_íngua de tradição e língua técnica, Lisboa, Passagens, 1995.

SAUSSURE, Ferdinand de. Curso de linguiística geral, São Paulo, Cultrix 1991. . Cours de lingüístique générale, Paris, Payot,1968.

WITTGENSTEIN, Ludwig. Tratactus lógico-philosophicus, São Paulo, Edusp, 1993. . Investigações filosóficas, São Paulo, Abril Cultural, 1975. 